\title{
Change of Physiology and Emotion According to Plant-decoration Activity in Workers
}

\author{
Hye Sook Jang*, Gyung Mee Gim, Kwang Jin Kim, and Hyun Hwan Jung \\ National Institute of Horticultural \& Herbal Science, RDA, Wanju-gun 565-852, South Korea
}

\begin{abstract}
This study was conducted to investigate the change of workers physiology and sensitivity according to the plant decoration activity using electroencephalographic (EEG), electrocardiogram, and semantic differential (SD) methods on 31 male and female workers in their twenties. Plant decoration activity and writing documents on a computer (WDOC) were carried out for 10 minutes each. The relative slow alpha power spectrum (RSA) has been highly exhibited at most measurement points at plant decoration activity compared to WDOC, and ratio of alpha to high beta spectrum (RAHB) was higher in the parietal lobe responsible for visual function in charge of visual function and showed stable and relaxed effect with little stress or tension. In addition, the relatively fast alpha power spectrum (RFA), which is responsible for visual function, after WDOC was higher than after plant decoration activity in the left parietal lobe $(P<.05)$. Although not statistically significant, the relative high beta power spectrum $(\mathrm{RHB})$ and the ratio of mid beta to theta (RMT), which are stress concentration indexes with tension, were highly regarded as a whole when performing WDOC. There was little difference in heart rate between after both activities. However, high frequency (HF) component indicating parasympathetic nervous system activity was more highly active after WDOC than Planting decoration activity, and the low frequency (LF) component indicating sympathetic nervous system activity tended to be lower after WDOC than after planting activity meaning that plant activity have a sense of stability than WDOC and these results were similar to brain wave analysis. In addition, the sense of comfort, naturalness, calm were significantly higher when the plant decoration activity was performed than when the WDOC was performed in the SD emotional vocabulary survey. These results could be interpreted that plant decoration activity induced more physiologically and psychologically stability and relaxation than WDOC, and enhanced attention ability in appropriate awakening state.
\end{abstract}

Keywords: high frequency, low frequency, psychology, electroencephalographic, electrocardiogram, semantic differential methods

\section{Introduction}

Behind rapid economic growth in Korea, there are workers who are not free from stress. Such stress from duties is recognized as a perceived dynamic state that involves uncertainty about a certain important thing, and as a psychological condition such as high blood pressure, headache, anxiety, sleeplessness, heart disease, nervous breakdown, tension, depression, etc. based on the concept of personal response (Schuler, 1980). At the same time, as workers use the Internet to

This study was supported by the 2017 Post-doctoral Fellowships Program of the National Institute of Horticultural and Herbal Science under the Rural Development Administration (PJ011376042017).

Received: September 4, 2017, Revised: September 15, 2017, Accepted: September 22, 2017

*Comesponding author: jhs915@korea.kr 
perform their duties at a workplace, and thus they are exposed to visual display terminals such as computers for a long time, they are also likely to be exposed to a muscular skeletal disease, called "VDT (visual display terminal) syndrome" (Ong et al, 1987). Meanwhile, staying in an artificial indoor place with plants has both environmental and emotional effects such as psychological serenity and stress relief (Kwak, 2004; Lee, 2006). It was also reported that workers who have to stay indoors for most of the day and have little opportunities to see natural landscapes or plants through a window or inside their office tend to show a high level of anxiety and vigilance, which highlights the importance of creating a space with natural elements and indoor plants (Kim, 1998). Plants arouse people's curiosity and make them have various questions about and become interested in the process of plants' growing (Tak, 2004). Since plants do not grow or develop overnight, people have to wait and watch the process of growth, and they become more curious about and interested in the next step in the growth of plants (Lee, 2006).

In particular, people experience the purification of emotions and become emotionally stable through plants, and such psychological stability is a first-hand experience obtained from the living green nature, not from machines, which provides opportunities for having a mature ego for them (Kwack and Lee, 1999). In a study on education programs using plants, people experienced pleasure, a sense of stability, confidence, and satisfaction in the process of creating their own work, and the level of concentration, creativity and their interest and understanding of plants increased, which in turn increased their interest in learning about plants and provided positive effects (Kim, 2001). In another study conducted among people who showed a certain level of depression, it was found that a forest healing camp of 3 days and 2 nights and forest experience after that had a positive impact on their physiological stability (Shin et al., 2007). Likewise, horticultural activities reduce stress, and experiences of growing plants and watching the growth and development of plants improve emotional health and psychological stability, give the joy of life and help people recover from fatigue (Matuso and Relf, 1994). In addition, horticultural activities and garden plants reduce the level of stress, and keep calmness (Kaplan, 2001), and they are effective for psychological treatment and resilience (Ulrich, 1984). Horticultural activities can improve sociality, mental health, and self-esteem (Yun and Yoo, 2011), and such opportunities for voluntary activities improve the quality of life, and emotional stability (Choi, 2003; Hong, 2006).

Earlier studies on the psychological effects of horticultural activities measured personal responses through psychological surveys and questionnaire surveys for sociological research in order to examine the effects of watching plants, and doing activities using plants on the health of the body. Horticultural activities, however, are intuitive and non-verbal activities that stimulate five senses, and thus it is necessary to examine physiological responses in order to lay a scientific foundation for such effects (Lee et al., 2011). In this regard, this study aimed to verify the psychophysiological effects of decoration activities using plants easily accessible by workers who are exposed to computers for a long time and under stress at a workplace in a scientific way.

\section{Methods}

\section{Selection of subjects}

Changes in the physiological and emotional states of workers depending on plant decoration and document writing activities were examined using electroencephalographic (EEG), electrocardiogram (ECG), and semantic differential (SD) methods. Subjects were selected among workers who were suitable for general brain research, using offline notice boards in the National Institute of Horticultural and Herbal Science. They were selected among those who were right-handed, had no mental disease, visual impairment and brain disease, and did not take medicines (Lee et al., 2009; Son et al., 1998, 1999). A total of 31 participants (14 males and 17 females) aged $26.5( \pm 3.5)$ years on average were selected, and they were 
sufficiently informed of the purpose, measurement items and methods of this study. They participated in this research after signing a voluntary participation consent form. They were instructed not to drink alcohol from two days before this experiment, and sny beverage that stimulates the brain such as coffee, green tea, caffeine drinks from two hours before this experiment.

\section{Environmental conditions in the experimental room}

Electroencephalographic (EEG), electrocardiogram (ECG), and semantic differential (SD) analysis were conducted in a research room in the National Institute of Horticultural and Herbal Science between 10am and 4pm (Fig. 2). A desk was placed in the light gray room (length $3.5 \mathrm{~m}$, width $3.0 \mathrm{~m}$, height $2.6 \mathrm{~m}$ ), and the intensity of illumination at the desk height was $400 \pm 10$ lux on average (UT383 Mini Light Meters, Japan). The temperature and humidity in the room were $25 \pm 0.5^{\circ} \mathrm{C}$ and $70 \pm 10 \%$ respectively (TR-72Ui, T\&D CORP., Japan). Light from outside was blocked to prevent its impact on the psychology of subjects, and the fluorescent light on the ceiling was turned on.

\section{Materials and methods}

Subjects performed two types of activities for 10 minutes respectively: decorating a glass container (diameter $30 \mathrm{~cm}$ ) with plants, and writing a document. Changes before and after the two activities were measured. For the plant decoration activity, three indoor foliage plants (Anthurium andraeanum, Davallia mariesii, Trachelospermun asiaticum), one 30 $\mathrm{cm}$-diameter glass container, fresh moss, two little rabbit ornaments and volcanic stones were used to create a plant decoration. For the document writing activity, subjects were instructed to type a given text. Before and after each activity, their EEG and ECG were measured two times, in total 4 times (Kim, 1998; Jang et al., 2014), and SD analysis was conducted after each activity only (Fig. 1,2). To compare the two activities, the document writing activity was set as the control group. An EEG and ECG device (BIOS-S24, BioBrain Inc., Daejeon, Korea) was placed $30 \mathrm{~cm}$ behind subjects. Once a subject entered the EEG experimental room, he or she was informed of the overall process of the experiment, and signed a research consent form. While 12 electrodes were attached on the head, subjects were allowed to get used to the internal environment. Cup electrodes were attached to 8 channels for the frontal lobes $(F)$, the temporal lobes $(T)$, the

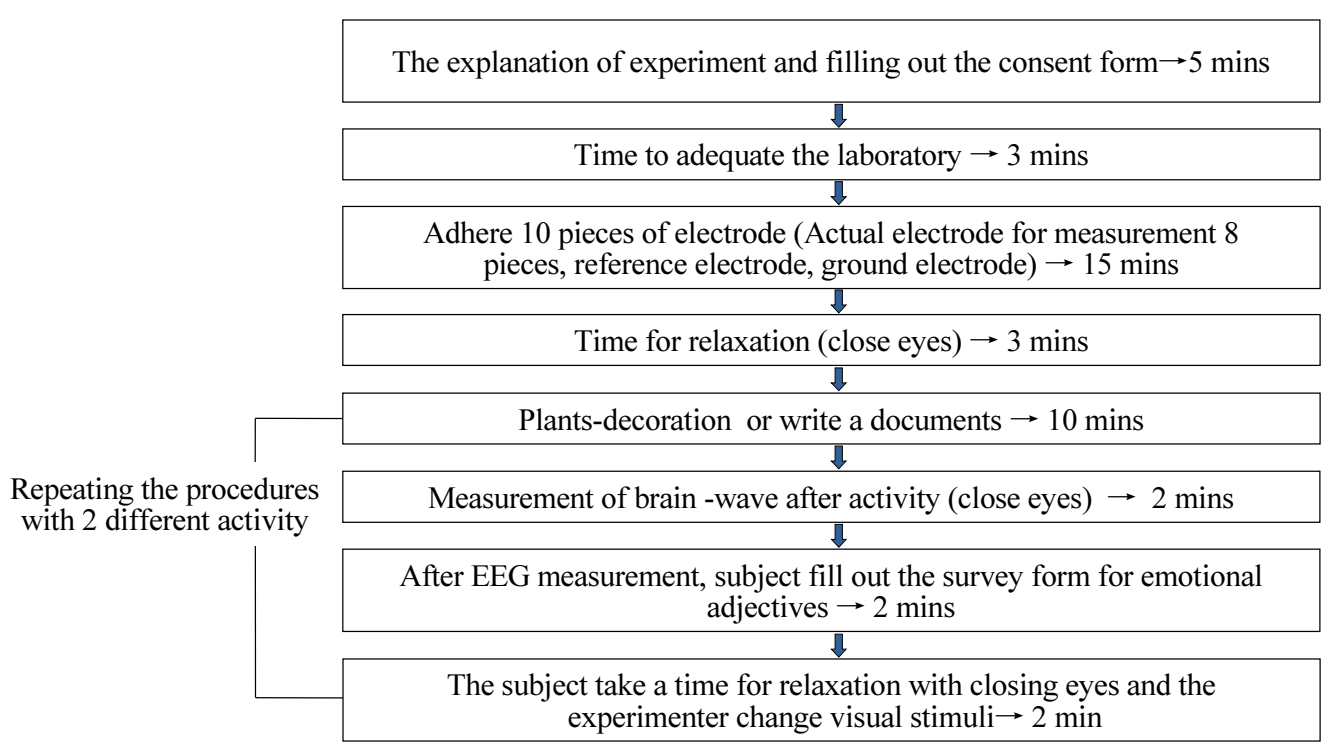

Figure 1. Experimental procedure for electroencephalography visual stimuli. 


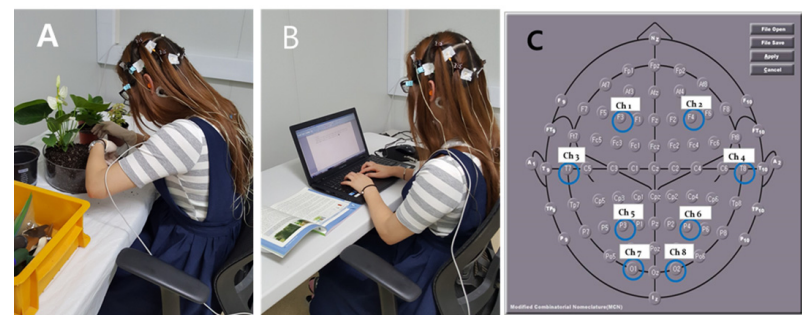

Figure 2. Activity experiment used electroencephalography device. (A) Plants-decoration Activity; (B) write a documents; positions of 8 electrodes on the top view of the scalp (C) used for measurement of electroencephalography and 2 channels of electrocardiography.

parietal lobes $(\mathrm{P})$, and the occipital lobes $(\mathrm{O})$, and 1 reference electrode and 1 ground electrode behind the two ears respectively, 1 disposable ECG electrode below the left chest, and 1 disposable ECG electrode above the right chest (Fig. 1-3). Cup electrodes are a disc-type electrode coated with gold, and they were attached after cleaning dirts off the skin surface to minimize their contact resistance with the skin using a EEG conductive paste (Elefix z-401ce, 2016, Nihon Kohden, Japan). They wore earplugs in order to prevent them from being exposed to noise from outside. Before measuring, they were instructed to close their eyes for the first 3 minutes to take a rest, and while they were taking a rest, materials for the first activity were placed on a desk (length 120, width 45, height $70 \mathrm{~cm}$ ). The two activities were randomly peformed without any order between the two activities. To ensure subjects do not see the materials of the second activity in advance, the materials were prepared in a separate room next to the EEG experimental room, and one activity was performed at a time. The EEG of the subjects was measured before and after each activity for 2 minutes and 10 seconds, and the SD questionnaire survey, for 2 minutes. After answering the questionnaire, subjects were instructed to close their eyes for 2 minutes again to take a rest. The same process was performed for the other activity. The materials for the second activity were promptly placed on the table for the two minutes when the subjects closed their eyes to take a rest. It took a total of 60 minutes to conduct the entire process for each subject (Fig. 1, 2).

\section{Semantic differential (SD) analysis}

Semantic differential (SD) is a method widely used to assess landscapes of which relationships with emotional adjectives or factors that are obtained through factor analysis are difficult to quantify due to the subjective preference of individuals (Kim, 2012; Park, 2010). SD analysis in this study was conducted using 3 pairs of emotional adjectives that were used to assess landscapes in earlier studies and associated with plants as shown in Table 6 (Im, 2009). A 7-point likert scale (from 1 (strongly disagree) to 7 (strongly agree)) and a SD method suggested by an American psychologist, Osgood et al. (1957) and widely used to assess emotions or landscapes, were used for the questionnaire survey in this study (Kim, 2012; Park, 2010).

\section{Statistical analysis}

Statistical analysis in this study was performed using IBM SPSS ver. 20.0, and to verify the reliability of the measurement tool, Cronbach's $\alpha$ was calculated. The results of EEG and ECG were statistically analyzed using relative power ratio, and emotional adjectives for SD, using the paired sample t-test; and the preference of activities, using the paired sample t-test and frequency analysis. 


\section{Results and Discussion}

\section{Changes in the EEG of workers depending on plant decoration and document writing activities}

To examine changes in the psychophysiological conditions of workers after doing activities using plants, plant the plant decoration and document writing activities were performed for 10 minutes respectively. The EEG and ECG of subjects were measured before and after performing the activities, and differences between them were compared (Table 1-3, Fig. 1-3). It was found that the relative slow alpha power spectrum (RSA), an indicator of stability and relaxation, after performing the plant decoration activity was statistically significantly high, compared to the document writing activity, in the frontal lobes (T3, T4) that control the comprehensive functions of the brain including the ability of thinking; in the parietal lobes $(\mathrm{P} 3, \mathrm{P} 4)$ that plays an important role in visual and spatial processing; and in the occipital lobe in the left hemisphere $(\mathrm{O} 1)(p<.05)$. In addition, the ratio of alpha to high beta (RAHB) was statistically significantly high in the parietal lobes (P3, P4), which indicates that the level of stability and relaxation increased in the state of almost no stress or tension. These results show that the level of RSA and RAHB after performing the document writing activity was statistically significantly high, compared to the plant decoration activity, in the frontal lobes, the parietal lobes, and occipital lobes. The results are attributable to the fact that the activity of the frontal lobes that provide high-level recognition, emotions and mental functions; the parietal lobes that control visual organs; and the occipital lobes increased. The results coincide with those of Kim et al. $(2002)$ and Son et al. $(1998,1999)$ that the visual elements of plants indoors increased the ratio of alpha, having positive effects on the activity of brain functions and psychophysiological conditions. However, the RFA that control visual functions after performing the document writing activity was statistically significantly high, compared to the plant decoration activity, in the parietal lobe (P3) in the left hemisphere, which indicates that the level of immersion while writing a document was higher than decorating plants. The relative high beta power spectrum (RHB) after performing the document writing activity was relatively higher overall than the plant decoration activity, although it was not statistically significant. These results can be interpreted that the document writing activity shows a higher level of concentration than the plant decoration activity, actively absorbs information about things,

Table 1. Change of brain-wave ( $t$-value before- $t$-value after) with plants- decoration and writing documents on a computer.

\begin{tabular}{lccccccccc}
\hline \multicolumn{1}{c}{ EEG $^{\mathrm{z}}$} & $\mathrm{T}^{\mathrm{y}}$ & $\mathrm{F} 3$ & $\mathrm{~F} 4$ & $\mathrm{~T} 3$ & $\mathrm{~T} 4$ & $\mathrm{P} 3$ & $\mathrm{P} 4$ & $\mathrm{O} 1$ & $\mathrm{O} 2$ \\
\hline RSA & A vs. B & $2.283^{* \mathrm{x}}$ & $2.808^{* *}$ & 1.646 & 1.005 & $3.081^{* *}$ & $2.293^{*}$ & $2.297^{*}$ & 0.935 \\
RFA & A vs. B & -0.905 & -1.342 & -1.843 & -1.439 & $-2.378^{*}$ & -1.669 & -1.539 & -1.255 \\
RAHB & A vs. B & 1.032 & 1.930 & 0.196 & -0.307 & $2.533^{*}$ & $2.069^{*}$ & -0.136 & -1.639 \\
RHB & A vs. B & -0.487 & -1.455 & -0.464 & 0.435 & -1.662 & -1.567 & -1.283 & 0.165 \\
RST & A vs. B & -0.389 & -1.359 & -0.190 & -0.643 & -0.620 & -0.828 & -0.703 & 0.733 \\
RMT & A vs. B & 0.115 & -1.217 & 0.319 & -0.837 & -0.602 & -0.714 & 0.146 & -0.878 \\
RSMT & A vs. B & -0.175 & -1.522 & 0.195 & -0.806 & -0.747 & -0.934 & -0.545 & 0.474 \\
SEF50 & A vs. B & 0.237 & -1.016 & 0.363 & 0.207 & 0.187 & -0.393 & 0.119 & -1.089 \\
\hline
\end{tabular}

${ }^{\mathrm{z}}$ Electroencephalography (EEG); relative slow alpha power spectrum (RSA); relative fast alpha power spectrum (RFA); ratio of alpha to high beta (RAHB); relative high beta power spectrum (RHB); ratio of SMR to theta (RST); ratio of mid beta to theta (RMT); ratio of (SMR Mid Beta) to theta (RSMT); spectral edge frequency 50\% (SEF50); (A) plants decoration activity; (B) write a documents.

${ }^{\mathrm{y}} \mathrm{T}$ : Treatment; F: frontal lobes; T: temporal lobe; P: parietal lobes; $\mathrm{O}$ : occipital lobes; odd and even numbers indicate left and right hemispheres, respectively.

$* p<.05, * * p<.01$, respectively, by paired $t$-test $(\mathrm{n}=31)$. 
and improves concentration significantly, but that it also increases the activity of the brain as well as tension and anxiety. Yoon (2001) pointed out that even the act of watching green plants indoors reduced visual fatigue, changed brainwaves, and thus increased concentration, and Lee and Son (1999) also found that the act of watching green plants soothed the mind, released tension, and activated the functions of the brain, thus giving comfortable and happy feelings to humans. These results support those of this study that the plant decoration activity was more effective for stability and relaxation than the document writing activity.

Changes in the brainwaves of subjects after performing the plant decoration and document writing activities were examined through brain maps. The ratio of SMR to theta (RST), the ratio of mid beta to theta (RMT), the ratio of (SMR Mid Beta) to theta (RSMT), and SEF50 (spectral edge frequency 50\%), an indicator of brain activity were not statistically significant, but indicators for stability and relaxation, including RST, RSMT and SEF50, after performing the plant decoration activity were relatively higher than the document writing activity. The level of RMT, an indicator of concentration accompanied by tension, tended to decrease more after performing the plant decoration activity than the document writing activity. In particular, the level of RMT is in general clearly higher in the right hemisphere that controls emotional responses, than in the left hemisphere that controls rational responses (Kim and Chang, 2001; Kimura, 1973), and thus tends to be accompanied by tension from an emotional aspect, rather than from a logical and rational aspect. The

Table 2. Change of brain wave with plant decoration and writing documents on a computer.

\begin{tabular}{|c|c|c|c|c|c|c|c|c|c|}
\hline $\mathrm{EEG}^{\mathrm{z}}$ & $\mathrm{T}^{\mathrm{y}}$ & F3 & F4 & $\mathrm{T} 3$ & $\mathrm{~T} 4$ & P3 & P4 & $\mathrm{O} 1$ & $\mathrm{O} 2$ \\
\hline \multirow{2}{*}{ RSA } & A & $0.058^{\mathrm{x}}$ & 0.064 & 0.037 & 0.040 & 0.070 & 0.060 & 0.077 & 0.046 \\
\hline & $\mathrm{B}$ & -0.011 & -0.009 & 0.002 & 0.014 & 0.013 & 0.004 & 0.037 & 0.024 \\
\hline \multirow{2}{*}{ RFA } & A & -0.016 & -0.019 & -0.021 & -0.017 & -0.036 & -0.030 & -0.029 & -0.024 \\
\hline & B & -0.008 & -0.006 & -0.008 & -0.006 & -0.016 & -0.016 & -0.018 & -0.012 \\
\hline \multirow{2}{*}{ RAHB } & A & 1.053 & 1.618 & 0.068 & 0.679 & 1.644 & 1.910 & 1.070 & -0.379 \\
\hline & B & 0.177 & 0.224 & -0.055 & 0.917 & 0.350 & 0.626 & 1.170 & 1.261 \\
\hline \multirow{2}{*}{ RHB } & A & -0.001 & -0.007 & 0.003 & 0.001 & -0.010 & -0.009 & -0.012 & -0.005 \\
\hline & B & 0.003 & 0.002 & 0.009 & -0.004 & 0.001 & 0.002 & -0.004 & -0.006 \\
\hline \multirow{2}{*}{ RST } & $\mathrm{A}$ & 0.006 & -0.014 & -0.013 & -0.050 & -0.064 & -0.050 & -0.033 & 0.260 \\
\hline & B & 0.018 & 0.054 & -0.005 & -0.007 & -0.022 & -0.011 & 0.045 & 0.078 \\
\hline \multirow{2}{*}{ RMT } & A & 0.054 & 0.039 & 0.050 & 0.001 & 0.029 & 0.017 & 0.019 & 0.028 \\
\hline & B & 0.049 & 0.086 & 0.018 & 0.079 & 0.052 & 0.048 & 0.012 & 0.084 \\
\hline \multirow{2}{*}{ RSMT } & A & 0.059 & 0.025 & 0.038 & -0.049 & -0.035 & -0.034 & -0.015 & 0.289 \\
\hline & B & 0.068 & 0.140 & 0.013 & 0.072 & 0.030 & 0.037 & 0.057 & 0.161 \\
\hline \multirow{2}{*}{ SEF50 } & A & 0.350 & -0.114 & 1.088 & 0.320 & 0.270 & 0.064 & -0.321 & -0.405 \\
\hline & $\mathrm{B}$ & 0.194 & 0.344 & 0.775 & 0.149 & 0.190 & 0.180 & -0.348 & -0.032 \\
\hline
\end{tabular}

${ }^{\mathrm{z}}$ Electroencephalography (EEG); relative slow alpha power spectrum (RSA); relative fast alpha power spectrum (RFA); ratio of alpha to high beta (RAHB); relative high beta power spectrum (RHB); ratio of SMR to theta (RST); ratio of mid beta to theta (RMT); ratio of (SMR Mid Beta) to theta (RSMT); spectral edge frequency 50\% (SEF50); (A) Value after plants decoration activity minus value before the activity; (B) Value after write a documents minus value before the write a documents.

${ }^{\mathrm{y}} \mathrm{T}$ : Treatment; F: frontal lobes; $\mathrm{T}$ : temporal lobe; P: parietal lobes; O: occipital lobes; odd and even numbers indicate left and right hemispheres, respectively $(n=31)$.

${ }^{\mathrm{x}}$ value before-after. 
Table 3. Change of brain wave with plant decoration and writing documents on a computer.

\begin{tabular}{|c|c|c|c|c|c|c|c|c|c|}
\hline $\mathrm{EEG}^{\mathrm{z}}$ & $\mathrm{T}^{\mathrm{y}}$ & F3 & $\mathrm{F} 4$ & $\mathrm{~T} 3$ & $\mathrm{~T} 4$ & P3 & P4 & $\mathrm{O} 1$ & $\mathrm{O} 2$ \\
\hline \multirow{4}{*}{$\begin{array}{l}\mathrm{R} \\
\mathrm{S} \\
\mathrm{A}\end{array}$} & $P b^{x}$ & $0.384 \pm 0.17$ & $0.399 \pm 0.17$ & $0.313 \pm 0.13$ & $0.339 \pm 0.15$ & $0.384 \pm 0.16$ & $0.401 \pm 0.17$ & $0.419 \pm 0.18$ & $0.423 \pm 0.19$ \\
\hline & $\mathrm{Ib}$ & $0.436 \pm 0.14$ & $0.454 \pm 0.15$ & $0.344 \pm 0.11$ & $0.359 \pm 0.14$ & $0.426 \pm 0.13$ & $0.439 \pm 0.13$ & $0.467 \pm 0.16$ & $0.452 \pm 0.15$ \\
\hline & $\mathrm{Pa}$ & $0.441 \pm 0.14$ & $0.463 \pm 0.13$ & $0.350 \pm 0.12$ & $0.379 \pm 0.14$ & $0.453 \pm 0.13$ & $0.461 \pm 0.14$ & $0.496 \pm 0.15$ & $0.469 \pm 0.14$ \\
\hline & $\mathrm{Ia}$ & $0.435 \pm 0.13$ & $0.446 \pm 0.15$ & $0.346 \pm 0.12$ & $0.373 \pm 0.14$ & $0.439 \pm 0.13$ & $0.443 \pm 0.14$ & $0.504 \pm 0.15$ & $0.476 \pm 0.15$ \\
\hline \multirow{4}{*}{$\begin{array}{l}\mathrm{R} \\
\mathrm{F} \\
\mathrm{A}\end{array}$} & $\mathrm{Pb}$ & $0.077 \pm 0.07$ & $0.077 \pm 0.07$ & $0.082 \pm 0$ & $0.078 \pm 0.05$ & $0.109=$ & \pm 0.07 & 0.09 & 0.117 \\
\hline & $\mathrm{Ib}$ & $0.070 \pm 0.05$ & $0.066 \pm 0.05$ & $0.078 \pm 0.04$ & $0.073 \pm 0.04$ & $0.106 \pm 0.07$ & $0.105 \pm 0.06$ & $0.113 \pm 0.09$ & $0.107 \pm 0.09$ \\
\hline & $\mathrm{Pa}$ & $0.060 \pm 0.05$ & $0.057 \pm 0.06$ & $0.061 \pm 0.04$ & $0.061 \pm 0.04$ & $0.073 \pm 0.05$ & $0.075 \pm 0.05$ & $0.088 \pm 0.10$ & $0.093 \pm 0.12$ \\
\hline & Ia & $0.063 \pm 0.05$ & $0.060 \pm 0.05$ & $0.070 \pm 0.04$ & $0.067 \pm 0.05$ & $0.090 \pm 0.07$ & $0.089 \pm 0.06$ & $0.095 \pm 0.09$ & $0.095 \pm 0.09$ \\
\hline \multirow{4}{*}{$\begin{array}{l}\mathrm{R} \\
\mathrm{A} \\
\mathrm{H} \\
\mathrm{B}\end{array}$} & $\mathrm{Pb}$ & $8.336=$ & -6.73 & $4.718=$ & $5.417 \pm$ & 7.37 & 7.98 & 9.38 & 7.94 \\
\hline & $\mathrm{Ib}$ & $8.281 \pm 4.34$ & $9.113 \pm 5.72$ & $4.689 \pm 2.00$ & $5.263 \pm 3.26$ & $7.800 \pm 3.35$ & $8.138 \pm 3.41$ & $9.913 \pm 6.53$ & $8.958 \pm 7.22$ \\
\hline & $\mathrm{Pa}$ & $9.389 \pm 7.63$ & $10.254 \pm 7.19$ & $4.785 \pm 3.09$ & $6.096 \pm 4.50$ & $9.023 \pm 4.31$ & $9.890 \pm 5.85$ & $10.454 \pm 6.16$ & $9.042 \pm 6.05$ \\
\hline & $\mathrm{Ia}$ & $8.458 \pm 5.66$ & $9.338 \pm 7.06$ & $4.633 \pm 2.45$ & $6.180 \pm 4.52$ & $8.150 \pm 3.71$ & $8.764 \pm 4.90$ & $11.083 \pm 7.40$ & $10.219 \pm 8.03$ \\
\hline \multirow{4}{*}{$\begin{array}{l}\mathrm{R} \\
\mathrm{H} \\
\mathrm{B}\end{array}$} & $\mathrm{Pb}$ & 0.081 & 0.080 & 0.111 & 0.10 & 0.083 & 0.0 & 0.08 & $=0.06$ \\
\hline & $\mathrm{Ib}$ & $0.075 \pm 0.03$ & $0.075 \pm 0.04$ & $0.099 \pm 0.03$ & $0.101 \pm 0.04$ & $0.078 \pm 0.03$ & $0.077 \pm 0.03$ & $0.079 \pm 0.04$ & $0.091 \pm 0.05$ \\
\hline & $\mathrm{Pa}$ & $0.079 \pm 0.05$ & $0.073 \pm 0.04$ & $0.114 \pm 0.06$ & $0.101 \pm 0.05$ & $0.074 \pm 0.04$ & $0.073 \pm 0.04$ & $0.071 \pm 0.03$ & $0.085 \pm 0.06$ \\
\hline & $\mathrm{Ia}$ & $0.077 \pm 0.04$ & $0.078 \pm 0.04$ & $0.109 \pm 0.04$ & $0.096 \pm 0.05$ & $0.080 \pm 0.04$ & $0.079 \pm 0.04$ & $0.075 \pm 0.04$ & $0.085 \pm 0.05$ \\
\hline \multirow{4}{*}{$\begin{array}{l}\mathrm{R} \\
\mathrm{S} \\
\mathrm{T}\end{array}$} & $\mathrm{Pb}$ & $0.256 \pm$ & 0.250 & 0.34 & 0.325 & 0.38 & 0.35 & 0.510 & 0.59 \\
\hline & $\mathrm{Ib}$ & $0.219 \pm 0.10$ & $0.214 \pm 0.10$ & $0.319 \pm 0.17$ & $0.308 \pm 0.21$ & $0.379 \pm 0.27$ & $0.351 \pm 0.26$ & $0.491 \pm 0.43$ & $0.520 \pm 0.49$ \\
\hline & $\mathrm{Pa}$ & $0.261 \pm 0.25$ & $0.236 \pm 0.25$ & $0.333 \pm 0.21$ & $0.275 \pm 0.16$ & $0.320 \pm 0.20$ & $0.300 \pm 0.18$ & $0.477 \pm 0.65$ & $0.851 \pm 2.55$ \\
\hline & Ia & 0.238 & 0.26 & 0.3 & 0.3 & 0.3 & 0.3 & 0.5 & 0.88 \\
\hline \multirow{4}{*}{$\begin{array}{l}\mathrm{R} \\
\mathrm{M} \\
\mathrm{T}\end{array}$} & $\mathrm{Pb}$ & $0.362=$ & & & & 0.460 & 0.43 & 0 . & \pm 0.42 \\
\hline & $\mathrm{Ib}$ & $0.346 \pm 0.26$ & $0.339 \pm 0.20$ & $0.519 \pm 0.47$ & $0.425 \pm 0.25$ & $0.448 \pm 0.28$ & $0.427 \pm 0.24$ & $0.526 \pm 0.32$ & $0.556 \pm 0.32$ \\
\hline & $\mathrm{Pa}$ & $0.416 \pm 0.31$ & $0.394 \pm 0.30$ & $0.558 \pm 0.36$ & $0.495 \pm 0.35$ & $0.489 \pm 0.32$ & $0.453 \pm 0.27$ & $0.529 \pm 0.28$ & $0.588 \pm 0.32$ \\
\hline & Ia & $0.396 \pm 0.26$ & $0.425 \pm 0.33$ & $0.538 \pm 0.36$ & $0.503 \pm 0.42$ & $0.500 \pm 0.37$ & $0.475 \pm 0.30$ & $0.539 \pm 0.30$ & $0.639 \pm 0.43$ \\
\hline \multirow{4}{*}{$\begin{array}{c}\mathrm{R} \\
\mathrm{S} \\
\mathrm{M} \\
\mathrm{T}\end{array}$} & $\mathrm{Pb}$ & $0.618 \pm 0.39$ & 0.605 & 0.854 & 0.76 & 0.49 & 0.786 & 0.68 & $1.150 \pm 1.04$ \\
\hline & $\mathrm{Ib}$ & $0.566 \pm 0.33$ & $0.553 \pm 0.25$ & $0.838 \pm 0.62$ & $0.733 \pm 0.41$ & $0.827 \pm 0.45$ & $0.778 \pm 0.42$ & $1.017 \pm 0.63$ & $1.076 \pm 0.63$ \\
\hline & $\mathrm{Pa}$ & $0.677 \pm 0.50$ & $0.630 \pm 0.49$ & $0.891 \pm 0.55$ & $0.771 \pm 0.47$ & $0.808 \pm 0.48$ & $0.753 \pm 0.42$ & $1.006 \pm 0.77$ & $1.438 \pm 2.69$ \\
\hline & Ia & $0.634 \pm 0.37$ & $0.693 \pm 0.52$ & $0.852 \pm 0.48$ & $0.804 \pm 0.58$ & $0.857 \pm 0.64$ & $0.814 \pm 0.51$ & $1.075 \pm 0.95$ & $1.237 \pm 1.07$ \\
\hline \multirow{4}{*}{$\begin{array}{c}S \\
E \\
F \\
50\end{array}$} & $\mathrm{~Pb}$ & $10.214 \pm 2.62$ & $10.090 \pm 2.08$ & $10.976 \pm 3.36$ & $10.805 \pm 3.71$ & $10.239 \pm 1.58$ & $10.164 \pm 1.45$ & $10.343 \pm 1.32$ & $11.009 \pm 2.76$ \\
\hline & $\mathrm{Ib}$ & $9.783 \pm 0.72$ & $9.942 \pm 1.19$ & $10.642 \pm 2.01$ & $11.098 \pm 3.87$ & $10.131 \pm 0.78$ & $10.185 \pm 0.75$ & $10.477 \pm 1.20$ & $10.752 \pm 1.85$ \\
\hline & $\mathrm{Pa}$ & $10.564 \pm 3.31$ & $9.975 \pm 1.85$ & $12.064 \pm 4.66$ & $11.125 \pm 3.62$ & $10.509 \pm 2.90$ & $10.228 \pm 1.95$ & $10.022 \pm 0.79$ & $10.604 \pm 2.44$ \\
\hline & Ia & $9.977 \pm 1.59$ & $10.285 \pm 3.17$ & $11.417 \pm 3.74$ & $11.246 \pm 4.15$ & $10.321 \pm 1.81$ & $10.365 \pm 1.51$ & $10.129 \pm 0.79$ & $10.721 \pm 2.00$ \\
\hline
\end{tabular}

${ }^{\mathrm{z}}$ Electroencephalography (EEG); relative slow alpha power spectrum (RSA); relative fast alpha power spectrum (RFA); ratio of alpha to high beta (RAHB); relative high beta power spectrum (RHB); ratio of SMR to theta (RST); ratio of mid beta to theta (RMT); ratio of (SMR Mid Beta) to theta (RSMT); spectral edge frequency $50 \%$ (SEF50);

${ }^{\mathrm{y}}$ See Fig. 2. T: Treatment; F: frontal lobes; T: temporal lobe; P: parietal lobes; O: occipital lobes; odd and even numbers indicate left and right hemispheres, respectively.

${ }^{\mathrm{x}}(\mathrm{Pb})$ plants decoration activity; (Ib) write a documents; (Pa) plants decoration activity; (Ia) write a document; (Pb), (Ib): before value; (Pa), (Ia): after value; Mean \pm standard deviation $(\mathrm{n}=31)$. 


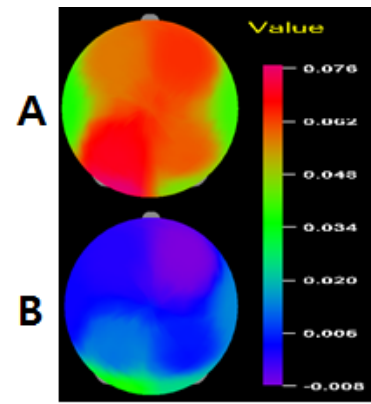

RSA

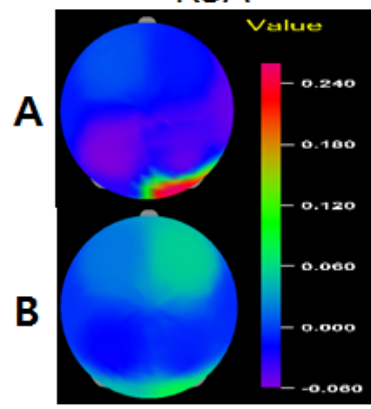

RST

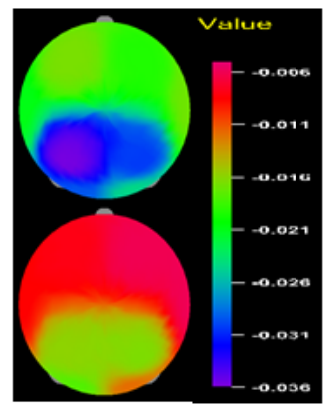

RFA

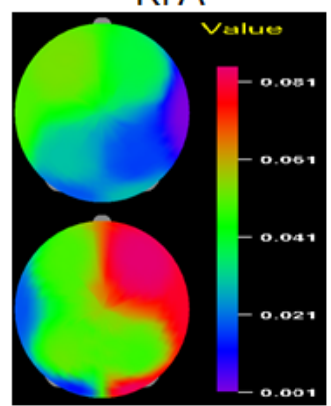

RMT

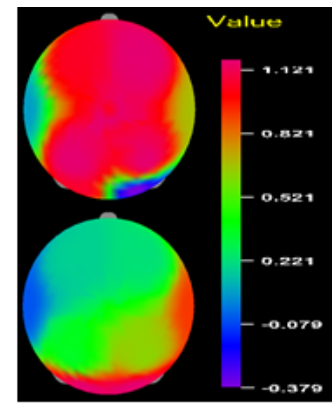

RAHB

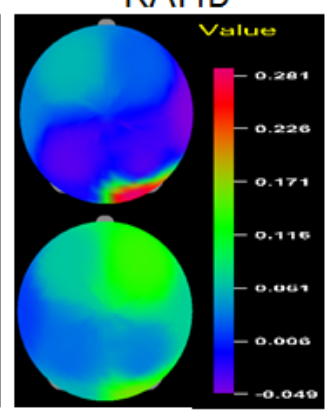

RSMT

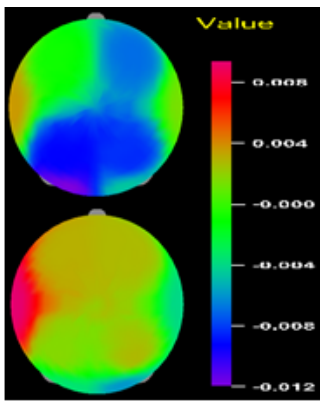

$\mathrm{RHB}$

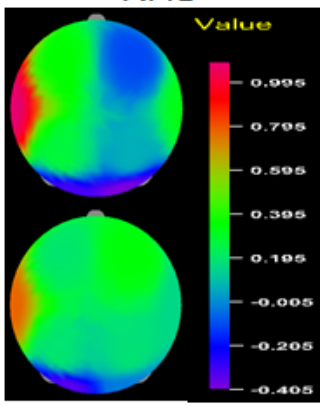

SEF50

Figure 3. Electroencephalographic (EEG) mapping (after-before: t-test value); blue and red indicate low and high electrical potential, respectively. Comparison of EEG voltages observed in response to (A) plants decoration activity; (B) write a documents; relative slow alpha power spectrum (RSA); relative fast alpha power spectrum (RFA); ratio of alpha to high beta (RAHB); relative high beta power spectrum (RHB) ratio of SMR to theta (RST); ratio of mid beta to theta (RMT); ratio of (SMR Mid Beta) to theta (RSMT); spectral edge frequency 50\% (SEF50).

results of Chang and Chen (2005) that the level of tension and vigilance of workers was high when there was no natural landscape or plant to be seen through windows in their office support those of this study that the level of tension was lower but the level of stability and relaxation was higher after performing the plant decoration activity than the document writing activity. Therefore, it seems that plant decoration activities using indoor plants are helpful to stabilize emotions particularly in an environment that requires a high level of concentration in a stable and relaxed condition such as an excessive use of devices like computers.

\section{Changes in the autonomic nervous system depending on plant decoration and document writing activities}

Changes in the autonomic nervous system depending on the plant decoration and document writing activities were analyzed, and there was almost no difference, as well as no statistically significant difference in the heart rate between the two activities (Fig. 4). However, the level of HF (high frequency) (Fig. 5), an indicator of the activity of the parasympathetic nervous system, was higher, and the level of LF (low frequency) (Fig. 6), an indicator of the activity of the sympathetic nervous system, was lower after performing the plant decoration activity than the document writing activity, which coincided with the results of the EEG. In addition, Lee et al. (2011) reported that the activity of the sympathetic nervous system decreased statistically significantly after performing horticultural activities which were found to be effective in stabilizing physiological conditions. The results were similar to those of this study that the level of the activity of the sympathetic nervous system was low, and that the level of the activity of the parasympathetic nervous system was high. 


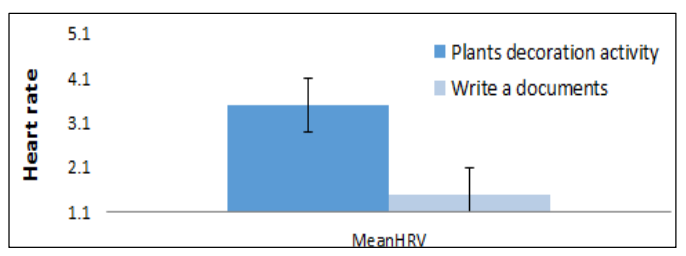

Figure 4. Change of heart rate with plants-decoration and writing documents on a computer.

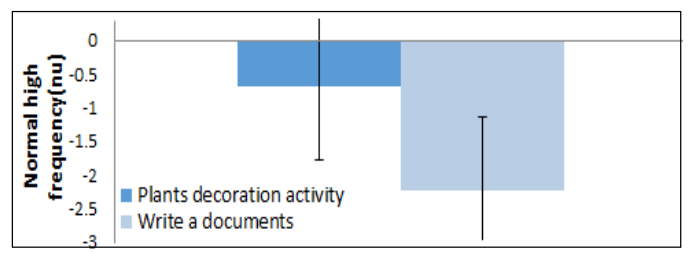

Figure 5. Change of parasympathetic nerve with plantsdecoration and writing documents on a computer.

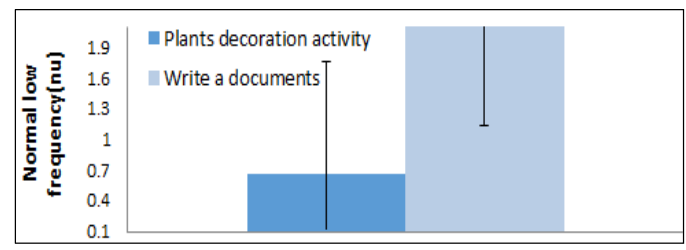

Figure 6. Change of sympathetic nerve with plants-decoration and writing documents on a computer.

\section{Preference of subjects depending on plant decoration and document writing activities}

The preference of subjects and the preference ratio between the plant decoration and document writing activities were analyzed (Table 4-5), and the mean preference level of the plant decoration activity (4.00/5) was statistically significantly higher than that of the document writing activity (2.58/5). In addition, the preference ratio of the plant decoration activity was high in the range of answers from "normal" to "highly preferred," while that of the document writing activity was high in the range of answers from "never preferred" to "normal." Out of the entire subjects, $81 \%$ answered that they preferred the plant decoration activity, and 52\% answered that they did not prefer the document writing activity.

\section{Changes in semantic differential (SD) depending on plant decoration and document writing activities}

Changes in emotions depending on the plant decoration and document writing activities were examined using semantic

Table 4. Preference of subject with plants-decoration and writing documents on a computer.

\begin{tabular}{llll}
\hline \multicolumn{1}{c}{ Treatment } & $\mathrm{N}$ & Mean & $\mathrm{SD}$ \\
\hline Plant decoration activity & 31 & $4.00^{\mathrm{z}}$ & 0.63 \\
Write a documents & 31 & 2.58 & 0.85 \\
$t$-value & & 7.706 & \\
$p$-value & & $0.000^{* * *}$ & \\
\hline
\end{tabular}

${ }^{\mathrm{z}}$ Likert scale: $1=$ Never preference; $5=$ Very preference.

$* * * p<.001$, respectively, by paired $t$-test $(\mathrm{n}=31)$.

Table 5. Preference ratio of subject with plants-decoration and writing documents on a computer.

\begin{tabular}{cccccc}
\hline & \multicolumn{5}{c}{ Preference (\%) } \\
\cline { 2 - 5 } $\mathrm{T}^{\mathrm{z}}$ & Never preferred & Not preferred & Normal & Preferred & Highly preferred \\
\hline $\mathrm{A}$ & 0.0 & 0.0 & 19.4 & 61.3 & 19.4 \\
$\mathrm{~B}$ & 6.5 & 45.2 & 32.3 & 16.1 & 0.0 \\
\hline
\end{tabular}

${ }^{\mathrm{z}}(\mathrm{T})$ Treatment; (A) plants decoration activity; (B) write a documents; $(\mathrm{n}=31)$. 
Table 6. Emotional quotient with plants -decoration and writing documents on a computer.

\begin{tabular}{lllc}
\hline \multicolumn{1}{c}{ Treatment } & Pleasant $^{\mathrm{z}}$ & Natural & Calm \\
\hline Plant decoration activity & 1.13 & 1.65 & 1.06 \\
Write a documents & -0.23 & -1.06 & 0.03 \\
$t$-value & 5.121 & 8.692 & 3.791 \\
$p$-value & $0.000^{* * *}$ & $0.000^{* * *}$ & $0.001^{* * *}$ \\
\hline
\end{tabular}

${ }^{\mathrm{z}}$ Effect of actovity: -3 = Very unpleasant; 3 = Very pleasant.

$* * * p<.001$, respectively, by paired $t$-test $(\mathrm{n}=31)$.

differential (SD) analysis (Table 6), and the level of "pleasant," "natural" and "calm" was statistically significantly higher after performing the plant decoration activity than the document writing activity $(p<.000)$. The emotional quotient of the plant decoration activity was 1.13 in "pleasant," 1.65 in "natural," and 1.06 in "calm," and that of the document writing activity, $-0.23,-1.06$, and 0.03 respectively. Some earlier studies (Kwak, 2004; Lee, 2006; Ulrich, 1981) reported that contacting plants in an artificial indoor space had both environmental and emotional effects such as psychological stability, calmness, reduced visual stress, etc., and Lee et al. (2011) also found that horticultural activities were more effective for psychological pleasantness, relaxation and stability than tasks requiring the use of computers. These results support those of this study that subjects felt more natural and calm when performing the plant decoration activity than the document writing activity.

\section{Conclusions}

This study aimed to examine changes in the physiological and emotional conditions of workers after performing plant decoration activities, and to do so, electroencephalographic (EEG), electrocardiogram (ECG), and semantic differential (SD) analysis were conducted on a total of 31 workers in their 20s. Subjects performed two types of activities for 10 minutes respectively: decorating a $30 \mathrm{~cm}$-diameter glass container with plants, and writing a document, and changes before and after the two activities were measured. The document writing activity was set as the control group, and the plant decoration activity was compared with the control group. The relative slow alpha power spectrum (RSA) after performing the plant decoration activity was higher at most measurement points than the document writing activity $(p<.05)$, and the level of ratio of alpha to high beta (RAHE) was high in the parietal lobes (P3, P4) that control visual functions, indicating that the plant decoration activity was effective for stability and relaxation hardly accompanied by stress and tension. In addition, the relative fast alpha power spectrum (RFA) that controls visual functions after performing the document writing activity was higher in the parietal lobe in the left hemisphere than the plant decoration activity, showing a high level of immersion $(p<.05)$. The relative high beta power spectrum (RHE) and the ratio of mid beta to theta (RMT), an indicator of concentration accompanied by tension, after performing the document writing activity were relatively higher than the plant decoration activity, although it was not statistically significant. There was almost no statistically significant difference in the heart rate between the two activities, but the level of HF (high frequency), an indicator of the activity of the parasympathetic nervous system, was higher, and the level of LF (low frequency), an indicator of the activity of the sympathetic nervous system, was lower after performing the plant decoration activity than the document writing activity. This showed that the plant decoration activity is more effective for stability than the document writing activity, and these results were similar to those of the EEG analysis. The results of SD analysis showed 
that the level of "pleasant," "natural" and "calm" was statistically significantly higher after performing the plant decoration activity than the document writing activity, which can be interpreted that the plant decoration activity was more effective for the psychophysiological stability and relaxation of workers, and the improvement of concentration in a proper state of awakening than the document writing activity.

\section{References}

Chang, C.Y. and P.K. Chen. 2005. Human response to window views and indoor plants in the workplace. HortScience 40(5):1354-1359.

Choi, Y.H. 2003. The effect of horticultural activity to reduce anxiety of the middle school student. MS Thesis, Silla Univ., Busan, Korea.

Hong, S.Y. 2006. Meta-analysis of the effects of horticultural therapy. MS Thesis, Hanyang Univ., Seoul, Korea.

Im, S.B. 2009. Theories in landscape analysis. Revised ed. Seoul, Korea: Seoul Natl. Univ., Press.

Jang, H.S., K.J. Kim, H.H. Jung, M. Khalekuzzaman, and E.H. Yoo. 2014. Effect of green interior office on emotional psychology of human. J. Korean Soc. People Plants Environ. 17(6):555-560. DOI: 10.11628/ksppe.2014.17.6.555

Kaplan, R. 2001. The nature of the view from home: Psychological benefits. Environ. Behav. 33(4):507-542. DOI: $10.1177 / 00139160121973115$

Kim, E.I. 1998. A study of sight-psychological effects by a color area of greenspace. J. Korean Inst. Landsc. Archit. 26(1):36-43.

Kim, E.I., S.H. Hwang, W.S. Shin, and K.W. Ahn. 2002. Physiological effect of forest types: focused on brain wave and pulsation. J. Korean Inst. For. Recreat. 6(2):43-48.

Kim, K.M. 2012. Study on the effects of forest healing according to types of recreational forests. PhD. Diss., Chungbuk Natl. Univ., Cheongju, Korea.

Kim, S.Y. 2001. Effect of horticultural therapy on the functional rehabilitation in hemiplegic patients after stroke. MS Thesis, Konkuk Univ., Seoul, Korea.

Kim, Y.J. and N.K. Chang. 2001. A study on the use of the prefrontal brain waves for the assessment of brain hemisphericity. Biol. Educ. 29(1):87-97.

Kimura, K. 1973. The asymmetry of the human brain. Sci. Am. 228(3):70-78.

Kwack, H.R. and J.S. Lee. 1999. Effect of indoor landscaping influencing on the human life and emotion. J. J. Korean Inst. Inter. Landsc. Archit. 1(1):87-95.

Kwak, S.O. 2004. A study on the environmental marketing for interior scape within apartment. PhD. Diss., Sangmyung Univ., Cheonan, Korea.

Lee, G.G. 2006. Visual preference in green roof sites. J. Korean Inst. Landsc. Archit. 34(5):32-38.

Lee, J.H., W.S. Shin, P.S. Yeoun, and R.W. Yoo. 2009. The influence of forest scenes on psychophysiological responses. J. Korean For. Soc. 98(1):88-93.

Lee, J.S. and K.C. Son. 1999. Effects of indoor plant and various colors stimuli on the changes of brain activity and emotional responses. Hortic. Environ. Biotecnol. 40(6):772-776.

Lee, J.S., Y.J. Chung, J.A. Bak, Y.H. Beak, Y. Cho, and M.H. Chang. 2011. Effect of horticultural activities with drawings on the emotional development and attentional ability of children in low-income broken families. J. Korean Soc. People Plants Environ. 14(1):1-7.

Matuso, E. and D. Relf. 1994. Horticulture in human life, culture and environment. Acta horticulturae.

Ong, C.N. and W.O. Phoon. 1987. Influence of age on VDT work. Ann. Acad. Med. Singapore 16(1):42-45.

Osgood, C.E., G.J. Suci, and P.H. Tannnenbaum. 1957. The measurement of meaning. Illinois, USA: Univ. Illinois Press. 
Park, B.J. 2010. Experimental approach of therapeutic effect of forest recreation activities - focused on viewing and walking in forest environments-. PhD. Diss., Chungnam Natl. Univ., Daejeon, Korea.

Schuler, R.S. 1980. Definition and conceptualization of stress in organizations. Organ. Behav. Hum. Perform. 25(2):184-215. DOI: 10.1016/0030-5073(80)90063-X

Shin, W.S., P.S. Yeoun, and J.H. Lee. 2007. The impact that a forest experience influences on a human mental state stability. J. Korean Inst. For. Recreat. 11(3):37-43.

Son, K.C., J.S. Lee, and J.E. Song. 1998. Effect of visual recognition of indoor plants on changes of human brain electroencephalography. Hortic. Environ. Biotecnol. 39(:6)858-862.

Son, K.C., J.S. Lee, and J.E. Song. 1999. Effect of visual recognition of Ficus benjamina and its photograph on changes of human brain electroencephalography and brain blood flow. Hortic. Environ. Biotecnol. 40(1):134-138.

Tak, Y.S. 2004. Effect of horticultural therapy using the flower arrangement in center. MS Thesis, Honam Univ., Gwangju, Korea.

Ulrich, R.S. 1981. Natural versus urban scenes: Some psychophysiological effects. Environ. Behav. 13(5):523-556. DOI: $10.1177 / 0013916581135001$

Ulrich, R.S. 1984. View through a window may influence recovery from surgery. Science 224(4647):20-21. DOI: $10.1126 /$ science. 6143402

Yoon, S.K. 2001. The effect of plans-culture working on changes in children's personality. MS Thesis, Seoul Natl. Univ. of Educ., Seoul, Korea.

Yun, E.J. and Y.K. Yoo. 2011. Effects of horticultural activity on the mental health, self-esteem, and sociality in children from low income family. J. Korean. Soc. People Plants Environ. 12(1):17-22. 